\title{
EFEITO DA ADUBAÇÃO POTÁSSICA NA PRODUTIVIDADE DA SOJA
}

\section{POTASSIUM FERTILIZATION EFFECT ON SOYBEAN YIELD}

\author{
Rodrigo dos Santos* \\ Giovanno Radel de Vargas**
}

\section{RESUMO}

Sendo o potássio um macro nutriente primário, sua deficiência no solo provoca grande decréscimo nas produtividades das culturas. Com o objetivo de determinar a viabilidade de uma adubação corretiva de potássio e a melhor época de se fazer essa adubação na cultura de soja, visando uma maior eficiência em solos com diagnóstico de deficiência, foi instalado este experimento na propriedade do Sr. Sérgio Drehmer, localizado no município de Corbélia, estado do Paraná. O delineamento utilizado foi de blocos ao acaso, com seis tratamentos e quatro repetições. Os tratamentos utilizados foram os seguintes: T1- variedade de soja V-Max RR com adubação potássica 25 dias pré-plantio; T2 - variedade de soja V-Max RR com adubação potássica 30 dias pós-plantio; T3 - variedade de soja Apolo RR com adubação potássica 25 dias pré-plantio; T4 - variedade de soja Apolo RR com adubação potássica 30 dias pós-plantio; T5 - Testemunha - variedade de soja V-Max RR, sem adubação corretiva de potássio e T6 - Testemunha - variedade de soja Apolo RR sem adubação corretiva de potássio. Para os tratamentos T1, T2, T3 e T4, a quantidade de $\mathrm{K} 2 \mathrm{O}$ foi de $150 \mathrm{~kg} \mathrm{ha}^{-1}$, utilizando como fonte o Cloreto de Potássio na dose de $250 \mathrm{~kg} \mathrm{ha}^{-1}$. Utilizou-se o método para elevar o Potássio a 3,5\% da CTC, para se calcular a quantidade do produto a ser utilizado. Não se encontrou diferença significativa entre os tratamentos com cloreto de potássio para as variáveis produtividade e massa de 1000 grãos.

Palavras-chave: Potássio. Época de aplicação. Produtividade.

\begin{abstract}
As potassium is a primary macronutrient, its deficiency in the soil causes large decrease in crop yields. This experiment was carried out in Mr. Sérgio Drehmer`s property in Corbelia, state of Paraná in order to determine the feasibility of corrective potassium fertilization and the best time to fertilize soybean to obtain greater efficiency in soils diagnosed with deficiency. The randomized design of the study included six treatment blocks and four replications. The treatment used were: T1-soybean variety V-Max RR with K fertilization 25 days pre-planting; T2 - variety of soybean RR V-Max with potassium fertilization 30 days after planting;
\end{abstract}

**Mestrado em Ciências do Solo pela Universidade Federal do Paraná. 
T3 - Apolo RR soybean variety potassium fertilization with 25 days pre-planting, T4 - Apolo RR soybean variety with $\mathrm{K}$ fertilization 30 days after planting; T5 Witness - variety of soy-V MaxRR without corrective potassium fertilization and T6 - Witness - variety of soybean Apolo RR without corrective potassium fertilization. For T1, T2, T3 and T4 the amount of K2O was $150 \mathrm{~kg}$ ha-1, using potassium chloride at a dose of $250 \mathrm{~kg}$ ha- 1 . The study used this method to raise potassium to $3.5 \%$ of CTC to estimate the quantity of product to be used. There was no significant difference between treatments with potassium chloride to the yield and mass of 1000 grains.

Keywords: Potassium. Time Application. Yield.

\section{Introdução}

A soja (Glycine max) é uma das principais fontes de proteína e óleo vegetal do mundo, sendo utilizada nas alimentações humana e animal por milênios. O crescimento da produção de soja no Brasil determinou uma série de mudanças no país, acelerando a mecanização da agricultura brasileira, a modernização do sistema de transportes, a expansão da fronteira agrícola, a profissionalização e incremento do comércio internacional, a modificação e enriquecimento da dieta alimentar dos brasileiros, a aceleração da urbanização do país, a interiorização da população brasileira, a tecnificação de outras culturas assim como impulsionou e interiorizou a agroindústria nacional (DALL'AGNOL; HIRAKURI, 2008).

$\mathrm{O}$ crescimento da produção e o aumento da capacidade competitiva da soja brasileira sempre estiveram associados aos avanços científicos e a disponibilização de tecnologias ao setor produtivo (VIDOR et al., 2004).

No meio agronômico, são comuns os trabalhos sobre modos de aplicação de fertilizantes, visando principalmente reduzir perdas e aumentar a eficiência de uso nas lavouras. No caso da adubação potássica, o cloreto de potássio $(\mathrm{KCl})$ é a principal fonte de K utilizada nas culturas produtoras de grãos no Brasil (LOPES, 2005). Este sal é altamente solúvel em água, e o íon $\mathrm{K}^{+}$apresenta baixa força de adsorção aos coloides do solo (RAIJ, 1991), o que faz com que o parcelamento de doses de $\mathrm{K}_{2} \mathrm{O}$ acima de 60 a $80 \mathrm{~kg} \mathrm{ha}^{-1}$ seja frequentemente recomendado, objetivando reduzir as perdas de $\mathrm{K}^{+}$por lixiviação e o efeito salino dos adubos sobre as sementes na instalação das culturas, com maior precaução com cultivos em solos arenosos (ALVAREZ, 1999; RAIJ et al., 1997).
O potássio normalmente não sofre lixiviação tão intensa quanto o nitrogênio e também não é fixado tão fortemente quanto fósforo, sendo o risco de lixiviação do $\mathrm{K}$ maior nos solos arenosos, influenciando seus teores críticos no solo e na planta (LANA et al., 2002). De maneira geral, os locais de maior concentração desse nutriente no solo coincidem com os locais de maior umidade, evidenciando seu caminhamento por fluxo de massa. Isto significa que a distribuição de potássio no solo correlaciona-se com a distribuição de água no solo, indicando que se pode ter elevado controle de sua localização no solo em função da disponibilidade de água, controlando consequentemente sua lixiviação (ZANINI, 1991). O fornecimento de potássio de forma localizada aumenta a probabilidade de perdas por lixiviação e eleva seu efeito salino, pela alta concentração em área restrita.

De acordo com MARSCHNER (1995), o potássio é o segundo nutriente mineral requerido pelas plantas em termos de quantidade, e não possui função estrutural no metabolismo vegetal, permanecendo quase totalmente na forma iônica nos tecidos. Como o K, nos restos vegetais, não fica incorporado às cadeias carbônicas da matéria orgânica do solo, após a colheita ou senescência das plantas ele volta rapidamente ao solo em forma prontamente disponível para as culturas (RAIJ et al., 1997), fazendo da palhada um reservatório expressivo de $\mathrm{K}$ no curto prazo no SPD (ROSOLEM et al., 2003). Portanto, especula-se sobre a possibilidade de se fazer a antecipação da adubação potássica da lavoura comercial no cultivo de espécies de cobertura manejadas no SPD.

Segundo Malavolta e Crocomo (1982), o potássio $(\mathrm{K})$ participa diretamente ou indiretamente de 
diversos processos bioquímicos envolvidos com o metabolismo de carboidratos, como a fotossíntese e a respiração, atuando como ativador de um grande número de enzimas encontradas na célula vegetal. Além disso, acredita-se que o $\mathrm{K}$ esteja envolvido em mecanismos de abertura e fechamento estomatal e que, ao apresentarem deficiência deste nutriente, os vegetais passam a absorver mais ativamente nitrogênio $(\mathrm{N})$, magnésio $(\mathrm{Mg})$ e cálcio $(\mathrm{Ca})$, com acúmulo de compostos nitrogenados livres. Huber e Arny (1985) relataram que o K possui grande relação com a redução da ocorrência e da severidade de doenças em plantas, agindo na redução do potencial de inóculo e elevando o acúmulo de fitoalexinas e fenóis ao redor dos sítios de infecção.

Com o objetivo de determinar a viabilidade de uma adubação corretiva de potássio e a melhor época de se fazer essa adubação na cultura de soja visando uma maior eficiência em solos com diagnóstico de deficiência, instalou-se este experimento, onde avaliamos o rendimento de grãos dos tratamentos e a massa de 1000 grãos.

\section{Material e métodos}

O estudo foi conduzido a campo na propriedade do senhor Sérgio Drehmer, localizada no município de Corbélia - PR, em um solo classificado como ARGISSOLO VERMELHO-AMARELO (EMBRAPA 2006), com alto teor de matéria orgânica e de Capacidade de Troca de Cátions (CTC). A altitude local é de $760 \mathrm{~m}$, longitude $53^{\circ} 57^{\prime} 121^{\prime}$ " W e latitude $25^{\circ} 06^{\prime} 957^{\prime \prime} \mathrm{S}$.

$\mathrm{O}$ experimento foi conduzido em blocos casualizados, com quatro repetições e seis tratamentos, totalizando 24 parcelas. Os tratamentos utilizados foram os seguintes: Tratamento 1 (T1)- variedade de soja V - Max RR com adubação potássica 25 dias pré-plantio; Tratamento 2 (T2) - variedade de soja V - Max RR com adubação potássica 30 dias pós-plantio; Tratamento 3 (T3) - variedade de soja Apolo RR com adubação potássica 25 dias pré-plantio; Tratamento 4 (T4) - variedade de soja Apolo RR com adubação potássica 30 dias pós-plantio; Tratamento 5 (T5) - Testemunha - variedade de soja V - Max RR, sem adubação corretiva de potássio e Tratamento 6 (T6) - Testemunha - variedade de soja Apolo RR sem adubação corretiva de potássio. Para os tratamentos T1, T2, T3 e T4 a quantidade de $\mathrm{K} 2 \mathrm{O}$ foi de $150 \mathrm{~kg} \mathrm{ha}^{-1}$, utilizando como fonte o cloreto de potássio.

No dia 01 de outubro de 2008, efetuou-se a adubação com cloreto de potássio, na dosagem de $250 \mathrm{~kg} \mathrm{ha}^{-1}$, nas parcelas onde a adubação foi em pré-plantio, dia 25 de outubro de 2008 foi realizada semeadura das cultivares, com adubação base de 0-20-20 de adubo N-P-K, objetivando uma população de 1000 plantas por hectare. Para as parcelas avaliadas, a adubação em pós-emergência, foi aplicado a lanço $250 \mathrm{~kg} \mathrm{ha}^{-1}$ de cloreto de potássio $(\mathrm{KCl})$ no dia 25 de novembro de 2008. As parcelas tinham dimensão de 3,5 m x 4,3 m totalizando $15 \mathrm{~m}^{2}$.

As sementes foram tratadas com inseticida a base de Thiamethoxam e Fipronil. Os tratos culturais e os controles fitossanitários de pragas, doenças e plantas daninhas foram realizadas de acordo com a indicação técnica para a cultura da soja no estado do Paraná (EMBRAPA, 2009).

Foram avaliados o rendimento de grãos em $\mathrm{kg} \mathrm{ha}^{-1}$ e a massa de 1000 grãos de cada tratamento a partir da área útil das parcelas que corresponde a $8,5 \mathrm{~m}^{2}$, a umidade dos grãos foi convertida em $13 \%$ para os cálculos de rendimento de grãos. Os resultados foram submetidos à analise de comparação de médias pelo teste de Tukey ao nível de 5\% de significância.

\section{Resultados e discussão}

De acordo com a análise de variância, envolvendo as duas cultivares, verificou-se que houve diferença significativa a $(\mathrm{P}>0,05)$ para a produtividade e peso de 1000 grãos. As médias de rendimento de grãos obtidas no experimento encontram-se na média estadual paranaense na safra 2008, que de acordo com a Companhia Nacional de Abastecimento foi de $2.519 \mathrm{~kg} \mathrm{ha}^{-1}$ (Conab, 2008). As cultivares utilizadas são de ciclo rápido, para plantios no cedo, onde não obtiveram boas condições de cultivo no ano de 2008 na região em que se instalou o experimento, os cultivos precoces sofreram déficit hídrico, ocasionando em uma redução de produtividade. 
Tabela 1 - Média dos tratamentos massa de 1000 grãos (g) e produtividade $\mathrm{kg} \mathrm{ha}^{-1}$ de cada cultivar, seguidas pelo resultado de comparação de médias pelo teste de Tukey

\begin{tabular}{lcc}
\hline Cultivar & Massa de 1000 grãos (g) & Produtividade kg ha ${ }^{-1}$ \\
\hline Apolo RR & $192 \mathrm{a}$ & $2783,00 \mathrm{a}$ \\
V-Max RR & $141 \mathrm{~b}$ & $2471,00 \mathrm{~b}$ \\
\hline Teste F & $* *$ & $* *$ \\
\hline $\begin{array}{l}\text { Médias seguidas de mesma letra, dentro de cada parâmetro analisado, não diferem entre si, pelo teste de } \\
\text { Tukey a 5\% de probabilidade de erro. }\end{array}$ \\
$* *$ e n.s. = significativo a 1\% de probabilidade de erro e não significativo, respectivamente.
\end{tabular}

A produtividade de uma cultivar é o resultado de combinação entre o fenótipo e o genótipo, ou seja, a relação entre a genética contida na semente e as condições ambientais em que ela esta inserida. Se o genótipo tem alto potencial produtivo, ele irá depender de um fenótipo e manejo favorável de acordo com suas necessidades para expressar seu potencial. Cada cultivar possui um genótipo diferente, por isso devem ser posicionado de acordo com as características de cada região em que melhor se adaptam. Algumas são mais tolerantes a doenças, outras a estresse hídrico, acamamento, e assim por diante. Então, um híbrido que foi mais produtivo que outro em certo ano ou região, não significa que no próximo ano ou em outra região ela não possa ser menos produtiva, já que as condições climáticas, a pressão de pragas e doenças, e até mesmo os investimentos e técnicas de manejo do agricultor na lavoura não são exatamente iguais de um ano para outro, o que ficou demonstrado neste caso pela superioridade da cultivar Apolo RR em relação a cultivar V-Max RR.

De acordo com as informações sobre as características da cultivar Apolo RR, seu ciclo é super precoce, de hábito indeterminado, alto índice de ramificação, e peso de 1000 sementes de em torno de 168 g podendo variar conforme o ambiente explorado pela cultivar, no caso desse experimento obtemos 192 g. A cultivar V-Max RR é considerada precoce, possui hábito de crescimento indeterminado, tolerante ao acamamento e massa de 1000 grãos de $182 \mathrm{~g}$ em boas condições para cultivo, podendo ser explicada a redução da massa de 1000 grãos nesse experimento para $142 \mathrm{~g}$ pelas condições de stress hídrico em algumas fases críticas da cultura.

Tabela 2 - Média das variáveis massa de 1000 grãos (g) e produtividade $\mathrm{kg} \mathrm{ha}^{-1}$ conforme os tratamentos na cultivar de soja V-Max RR, seguidas pelo resultado de comparação de médias pelo teste de Tukey.

\begin{tabular}{lcc}
\hline Tratamento & Massa de 1000 grãos $(\mathrm{g})$ & ${\text { Produtividade } \mathrm{kg} \mathrm{ha}^{-1}}^{-170,81 \mathrm{a}}$ \\
\hline KCl 25 dias pré-plantio & $165,83 \mathrm{a}$ & $2635,65 \mathrm{a}$ \\
KCl 30 dias pós- emergência & $164,37 \mathrm{a}$ & $2622,69 \mathrm{a}$ \\
Testemunha & 7,9 & $2624,00 \mathrm{a}$ \\
\hline C.V \% & n.s. & 5,1 \\
Teste F & n.s. \\
Médias seguidas de mesma letra, dentro de cada parâmetro analisado, não diferem entre si, pelo teste de \\
$\begin{array}{l}\text { Tukey a 5\% de probabilidade de erro. } \\
\text { n.s. = não significativo }\end{array}$
\end{tabular}


O coeficiente de variação encontrado para essa variável nesse estudo foi de $7,9 \%$, para produtividade e 5,1\% para massa de 1000 grãos, significando homogeneidade e baixa dispersão dos dados, de acordo com a classificação proposta por Gomes (1984).

As respostas de produtividade encontradas nesse experimento para a época mais adequada de aplicação de cloreto de potássio na cultura da soja no município de Corbelia, não se diferiram estatisticamente entre si, sendo que também não encontramos diferença significativa em relação à massa de 1000 grãos nos tratamentos. A maior produtividade encontrada se deu com o cloreto de potássio aplicado em pré-emergência, onde obtivemos 2635,65 $\mathrm{kg}$ de grãos por hectare, e a menor produtividade se deu quando não se disponibilizou cloreto de potássio para as plantas onde foi obtida média de $2624 \mathrm{~kg}$ $\mathrm{ha}^{-1}$ de grãos. Essa diferença foi muito pequena, de apenas $11,65 \mathrm{~kg} \mathrm{ha}^{-1}$, não justificando economicamente o custo da aplicação.

Folani e Rosolem (2008) realizaram trabalho com o objetivo de avaliar a produtividade de grãos e a acumulação de $\mathrm{K}$ na soja em função da antecipação da aplicação de fertilizante potássico na instalação do milheto em relação com o K aplicado na semeadura da soja subsequente no SPD durante três anos agrícolas em LATOSSOLO VERMELHO distroférrico de textura média, onde semeou-se milheto em setembro como cultura de cobertura, e a soja na primeira quinzena de dezembro. Foi utilizado $0,30,60$ e $90 \mathrm{~kg} \mathrm{ha}^{-1}$ de $\mathrm{K}_{2} \mathrm{O}$ no milheto, combinado com 0, 30, 60 e $90 \mathrm{~kg} \mathrm{ha}^{-1}$ de $\mathrm{K}_{2} \mathrm{O}$ na soja. Coletaram-se plantas de soja aos 25, 50, 75 e 100 dias após a emergência, e os grãos no final do ciclo, para a determinação do acúmulo de K e da produtividade. Chegaram a conclusão que a antecipação de 60 a $90 \mathrm{~kg} \mathrm{ha}^{-1}$ de $\mathrm{K}_{2} \mathrm{O}$ na semeadura do milheto não comprometeu o acúmulo de $\mathrm{K}$ na lavoura de soja. As máximas produtividades de soja foram alcançadas no primeiro e segundo ano com doses de 85 a $90 \mathrm{~kg} \mathrm{ha}^{-1}$ de $\mathrm{K}_{2} \mathrm{O}$, que poderiam ser antecipadas totalmente na semeadura da gramínea de cobertura. A aplicação antecipada de $\mathrm{KCl}$ na semeadura do milheto minimizou a exportação de K pela colheita de grãos de soja.

\section{Conclusões}

A produtividade da soja não foi alterada estatisticamente em função da aplicação em pós-emergência de cloreto de potássio.

Apesar de não haver diferenças estatísticas, observou-se que a maior produtividade encontrada se deu com o cloreto de potássio aplicado em pré-emergência, e a menor produtividade se deu quando não se disponibilizou cloreto de potássio para as plantas.

A produtividade e massa de mil grãos da soja variaram em função da cultivar.

As cultivares utilizadas, por serem precoces, sofreram com o déficit hídrico da região na ocasião da realização do experimento, o que fez com que houvesse redução na produtividade destas cultivares.

A cultivar Apolo RR se mostrou mais produtiva em relação à cultivar V-Max RR para as condições de solo e clima encontradas durante o experimento.

\section{Referências}

ALVAREZ, V. V. H.; NOVAIS, R. F.; BARROS, N. F.; CANTARUTTI, R. B.; LOPES, A. S. Interpretação dos resultados das análises de solo. RIBEIRO, A. C.;

DALL'AGNOL, A.; HIRAKURI, M. H. Realidade e perspectivas do Brasil na produção de alimentos e agroenergia, com ênfase a soja. Grupo Cultivar. Pelotas, 2008.

GUIMARÃES, P. T. G.; AlVAREZ, V. V. H. (Ed.). Recomendações para o uso de corretivos e fertilizantes em Minas Gerais: $5^{\text {a }}$ Aproximação. Viçosa: Universidade Federal de Viçosa, 1999.

EMBRAPA - EMPRESA BRASILEIRA DE PESQUISA AGROPECUÁRIA. Sistema brasileiro de classificação de solos. Brasília: Embrapa-Solos, 2006, 320p.

FOLANI, J. S. S.; ROSOLEM, C. A. Produtividade e acúmulo de potássio na soja em função da antecipação da adubação potássica no sistema de plantio direto. Revista Brasileira de Ciência do Solo, Viçosa, v.18, n.36, p. 4-7, 2008.

GOMES, P. R. Estatística moderna na pesquisa agropecuária. Piracicaba: Potafos, 1984.

HUBER, D. M.; ARNY, D. C. Interactions of potassium with plant disease. MUNSON, R. D. (Ed.) Potassium in agriculture. Madison: American Society of Agronomy, 1985. 
LANA, R. M. Q.; HAMAW, O. T.; LIMA, L. M. L.; ZANÃO, J. L. A. Resposta da soja a doses e modos de aplicação de potássio em solo de cerrado. Bioscience Journal, v. 8, p. 17-23, 2003.

LOPES, A. S. Reserva de minerais potássicos e produção de fertilizantes potássicos no Brasil. YAMADA, T.; ROBERTS, T. L. (Eds.). Potássio na agricultura brasileira. Piracicaba, Potafos, 2005.

MASCARENHAS, H. A. A.; TANAKA, R. T. Soja. RAIJ, B.; CANTARELA, H.; QUAGGIO, J.; A.; FURLANI, A. M. C. (Eds.). Recomendações de adubação e calagem para o Estado de São Paulo. 2 ed. Campinas, Instituto Agronômico de Campinas, Fundação IAC, 1997.

MALAVOLTA, E.; CROCOMO, O. J. O potássio e a planta. YAMADA, T.; IGUE, K.; MUZILLI, O.; USHERWOOD, N. R. (Ed.). O potássio na agricultura brasileira. Piracicaba: Instituto da Potassa \& Fosfato: Instituto Internacional da Potassa, 1982.

RAIJ, B.; CANTARELA, H.; QUAGGIO, J. A.; FURLANI, A. M. C. Recomendações de adubação e calagem para o Estado de São Paulo. 2 ed. Campinas, Instituto Agronômico de Campinas, Fundação IAC, 1997.

ROSOLEM, C. A.; CALONEGO, J. C.; FOLONI, J. S. S. Lixiviação de potássio da palha de coberturas de solo em função da quantidade de chuva recebida. Revista Brasileira Ciência do Solo, v. 15, n. 21, p. 5-9, 2003.

VIDOR, C.; FONTOURA, J. G.; MACEDO, J.; BALDONEDO, A., N.; MIN, T. Tecnologias de produção de soja região central do Brasil. Londrina: Embrapa, 2004.

ZANINI J. Distribuição de água e do íon $\mathrm{K}^{+}$no solo, aplicados por fertirrigação em gotejamento. II - Teores de $\mathrm{K}^{+}$no bulbo molhado. ITEM - Irrigação e Tecnologia Moderna, 1991. 